\title{
Comparative STUdies OF SELF- COMPACTING CONCRETE MADE WITH DIFFERENT GENERATIONS OF SUPERPLASTICIZERS
}

\author{
Raya Harkouss, Bilal Hamad \\ Civil and Environmental Engineering, American University of Beirut, P.O. Box: 11-0236, \\ Riad El-Solh, 1107 2020, Beirut, Lebanon \\ rhh18@aub.edu.lb
}

(Received 26 September 2014 - Accepted 11 March 2015)

\section{ABSTRACT}

Harkouss, R. and Hamad, B. 2016. Comparative studies of self-compacting concrete made with different generations of superplasticizers. Lebanese Science Journal, 17(2): 200-216.

Self-compacting concrete was created as an effective solution to problems associated to low quality consolidation. Successful self-compacting concrete (SCC) mixes are designed to flow freely and cohesively without the intervention of mechanical compaction. The research presented in this paper has as objective to find the effect of different types of superplasticizers on the performance of concrete mixes. The understanding of this technology was acquired through a comparative study of mixes made with second generation sulphonated naphthalene formaldehyde based superplasticizer and third generation polycarboxylate-based superplasticizer. To meet the pre-defined objectives, the research program was subdivided into two interdependent phases. Phase I studies the effect of second and third generation superplasticizer on the fresh and hardened properties of mortar mixes. Phase II studies the effect of second and third generation superplasticizer on the fresh and hardened properties of concrete mixes. The experimental outcomes revealed that third generation superplasticizers induce more efficient dispersion defined by superior consistency levels and increased hardened strengths.

Keywords: self-compacting concrete (SCC), high-strength concrete, concrete admixtures, second generation naphthalene-based superplasticizer, third generation polycarboxylate-based superplasticizer

\section{INTRODUCTION}

Self-compacting concrete (SCC) is a relatively advanced concrete technology that emerged in the 1980s as a response to the urgent need for a solution to the defects associated with inadequate consolidation. The idea of SCC revolves around the production of concrete mixes that have the ability to flow under the action of gravity and fill the formworks

http://dx.doi.org/10.22453/LSJ-017.2.200216

National Council for Scientific Research - Lebanon 2016C

1sj.cnrs.edu.lb/vol-17-no-2-2016/ 
completely without the assistance of mechanical compaction. An SCC mix can be considered as successful when despite high fluidity characteristics, stability can still be maintained.

In order to supply fresh concrete with high consistency properties, an alteration to the concrete mix design is required. The diverse mix proportioning methods found in the literature review (Gaimster \& Dixon, 2003; Domone et al., 1999; EFNARC, 2005) agreed on a common basis for SCC mix design, where high paste content and low coarse aggregate volumes are necessary to bring concrete to higher consistency levels. Although these basic principles were similar in all researches, the mix proportioning methods were widely different. The method developed by Peter Domone (2009) at the University College London (UCL) demonstrated effective and clear mix design recommendations and accordingly was adopted in the current study.

The comparative study of SCC mixes was conducted using two generations of superplasticizers to find the effect of each generation on the rheological and the hardened mechanical characteristics of concrete. The sulphonated naphthalene formaldehyde based admixture (SNF) was selected to represent the second generation superplasticizer regularly used in the production of workable concrete mixes. Second generation superplasticizers enhance the workability of concrete mixes through a mechanism known as the electrostatic dispersion (Dransfield, 2003).

The third generation PCE superplasticizer is the second type of admixture used in the comparative study to represent the new generation of admixture involved in the development of self consolidating concrete. Polycarboxylate ether based admixtures prevent the formation of concrete lumps and improve the consistency of concrete mixes having low water to cement ratios through the steric hindrance mechanism (Dransfield, 2003).

To comply with the recommendations of the UCL method (Domone, 2009), this study was subdivided into two interdependent phases. The objective of the first phase was to compare the effect of second generation sulphonated naphthalene-based admixture and third generation polycarboxylate-based admixture on the fresh and hardened properties of identically designed mortar mixes. In the second phase, concrete mixes made using the same mortar mix design from the previous stage and combined with a selected constant volume of coarse aggregate, were tested to investigate self-compactibility properties for variable types of admixtures. The research investigates the link between mortar properties found in Phase I and concrete properties resulting from Phase II. This research also aims to demonstrate that the steric hindrance dispersion mechanism, specific for third generation superplasticizers, provides SCC mixes with superior rheological properties.

The main hypothesis tested in this research questions the effect of the high consistency SCC on the hardened concrete properties when compared to identical concrete mixes made with second generation superplasticizer. The current study is significant in terms of the adopted methodology. The rheological and mechanical characteristics of SCC and normal concrete (NC) were compared by producing concrete mixes without the addition of any viscosity enhancers like fillers (fly ash, limestone powder, silica fume, etc.). Adding viscosity enhancers to the mixes affects the strength characteristics of concrete and introduces additional variables that render the comparison of the effect of superplasticizers obsolete. In contrast, the SCC and NC in this research were produced using the same constituents found in regular concrete mixes without the incorporation of any additives. 


\section{BACKGROUND: UCL MIX DESIGN METHOD}

Today, as revealed by several standards, no unique procedure has been established to be followed for mix design. Consequently, SCC producers started to adopt successful mix proportioning criteria presented in published papers. To proceed with the current research, an effective mix design method developed by Domone (2009), at the University College London (UCL), was adopted.

Mix design starts by selecting the appropriate filling and passing ability in addition to viscosity based on the type of structural elements being constructed in reference to EFNARC's classes (2002) found in Table 1 or Walraven's Table (2003) presented in Table 2.

TABLE 1

SCC Acceptance Criteria (EFNARC, 2002)

\begin{tabular}{|l|c|c|c|}
\hline Method & \multirow{2}{*}{ Unit } & \multicolumn{2}{|c|}{ Typical Range of Values } \\
\cline { 3 - 4 } & & Minimum & Maximum \\
\hline Slump Flow by Abrams Cone & $\mathrm{mm}$ & 650 & 800 \\
T50cm Slump Flow & $\mathrm{sec}$ & 2 & 5 \\
V-Funnel & $\mathrm{sec}$ & 6 & 12 \\
Time increase, V-Funnel at $\mathrm{t}_{5}$ min. & $\mathrm{sec}$ & 0 & 3 \\
L-Box & $\left(\mathrm{h}_{2} / \mathrm{h}_{1}\right)$ & 0.8 & 1.0 \\
\hline
\end{tabular}

TABLE 2

Structural Applicability of SCC with Specific Rheological Properties (Walraven, 2003)

\begin{tabular}{|c|c|c|c|c|}
\hline $\begin{array}{c}\text { V-Funnel Flow Time } \\
\text { (sec.) }\end{array}$ & EFNARC Class & \multicolumn{3}{|c|}{ Structural Application } \\
\hline $9-25$ & VF2 & Ramps & & $\begin{array}{c}\text { Tall and } \\
\text { Slender } \\
\text { Elements }\end{array}$ \\
\hline $5-9$ & VF1 & & Walls & \\
\hline $3-5$ & VF1 & Floors & Floors & Floors \\
\hline \multicolumn{2}{|c|}{$\begin{array}{l}\text { Slump Flow }(\mathrm{mm}) \\
\text { EFNARC Class }\end{array}$} & $\begin{array}{c}470-570 \\
-\end{array}$ & $\begin{array}{c}540-660 \\
\text { SF1 }\end{array}$ & $\begin{array}{c}630-800 \\
\text { SF2/SF3 }\end{array}$ \\
\hline
\end{tabular}

Since SCC contains high mortar volumes, Domone found that the behaviour of concrete can be correlated to that of mortar after collecting sufficient data from less complex and more extensive mortar testing. Having the adequate rheological properties specified and the coarse aggregate content chosen to fall in the range of $30 \%$ to $40 \%$ of the total concrete volume, the required mortar spread and flow rate (whenever applicable) can be found from the two graphs shown in Figures 1 and 2. 


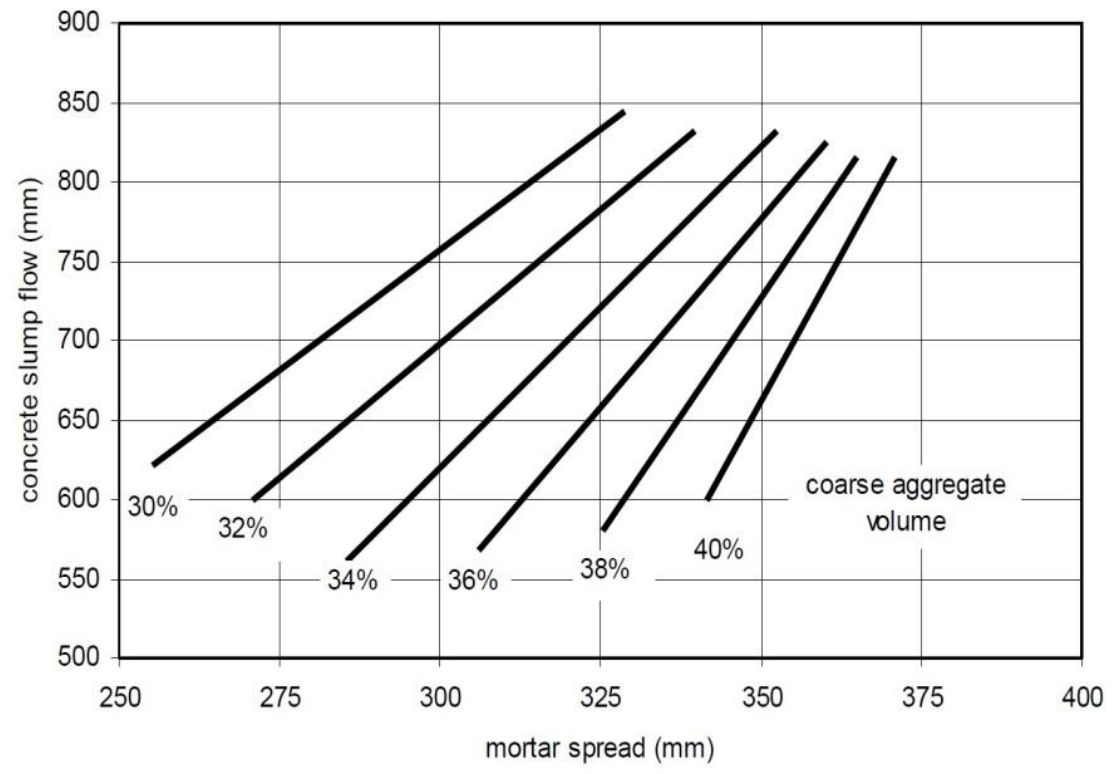

Figure 1. Concrete slump flow versus mortar spread diagram (Domone, 2009)

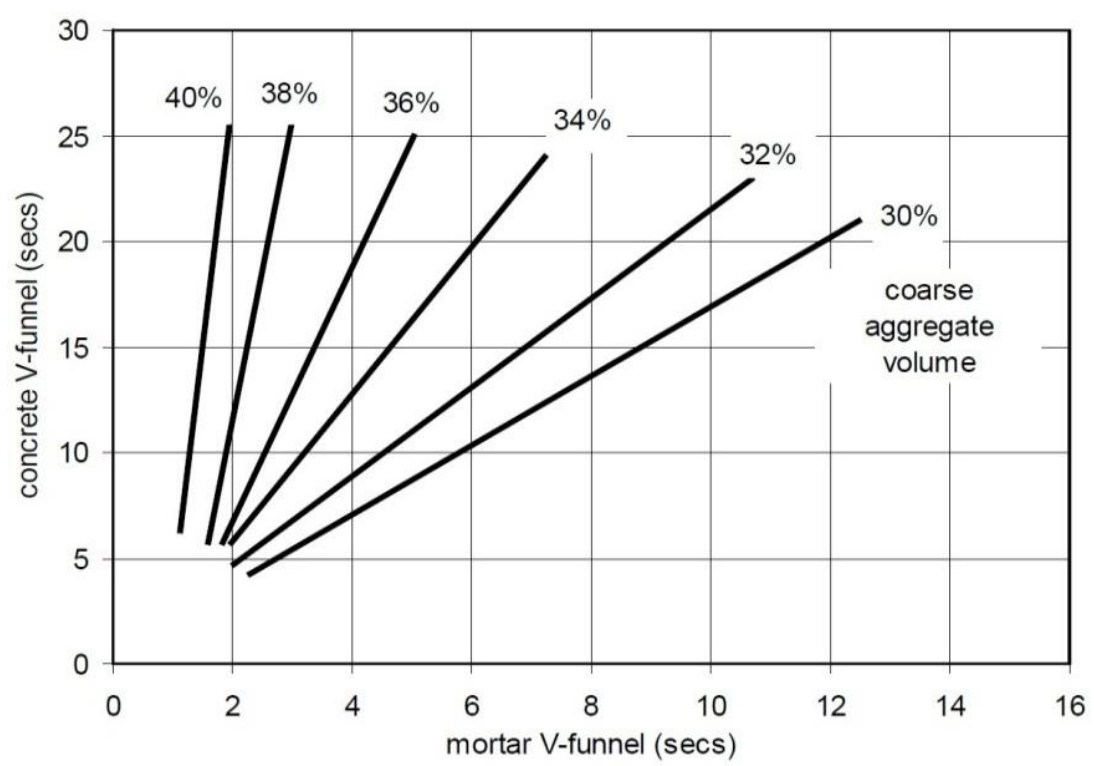

Figure 2. Concrete flow time versus mortar flow time diagram (Domone, 2009). 


\section{RESEARCH METHODOLOGY}

Phase I

In Phase I of this research, twenty-four small-scale mortar mixes were carried using either type of superplasticizers added at different dosages to compare the effect of each type of admixture on the consistency of mortars and to shed light on the response of mortars to constant increments in the percentage of superplasticizer. In all twenty-four mixes, the amount of cement, powder, and fine aggregates was kept constant. The only variable was the superplasticizer content. The flowability of mortars was measured using the mortar-specific spread cone and $\mathrm{V}$-funnel apparatus. The compressive strength at the age of 7 days was also tested using $7 \mathrm{~cm}$ hardened mortar cubes. The outcomes of this phase gave a good prediction on the behaviour of prospective concrete mixes executed in Phase II.

\section{Phase II}

The objective of Phase II was to compare the behaviour of identical concrete mixes made using different generations of superplasticizers in the fresh and hardened states. Seven concrete mixes were produced and tested. The slump, V-funnel and L-box tests were used to shed light on the fluidity characteristics of the different concrete mixes in the fresh state. In order to study the effect of enhanced fluidity on the hardened properties of concrete, one representative concrete mix was selected for each type of superplasticizer to study the hardened properties of identical concrete mixes containing the same percentage of admixture. Accordingly, cylindrical and plain (unreinforced) beam specimens were tested for the flexural, tensile and compressive strengths of concrete. The analysis of the results extracted from the two phases revealed a correlation between the rheological and the hardened characteristics of concrete and mortars.

\section{CONSTITUENT MATERIALS}

\section{Coarse aggregates}

The selection of the maximum size aggregate (MSA) and the volume to be occupied by coarse aggregates is controlled by the type of the structural element being cast, the density of the reinforcement and the respective flowability requirements (i.e. filling ability, passing ability and segregation resistance). In most applications, a MSA of $16 \mathrm{~mm}$ or $20 \mathrm{~mm}$ is considered as acceptable, whereas in thin structural elements, a MSA of $10 \mathrm{~mm}, 12 \mathrm{~mm}$ or 14 $\mathrm{mm}$ is recommended. In this research, and due to the absence in the Lebanese market of intermediate coarse aggregate categories falling between the $10 \mathrm{~mm}$ medium-size aggregate and the $20 \mathrm{~mm}$ coarse aggregate, the concrete mixtures were designed with crushed limestone aggregates having a MSA of $9.5 \mathrm{~mm}$.

Based on the ranges recommended for coarse aggregate content by the UCL method (Domone, 2009), EFNARC (2002), and ACI committee 237 (2007) for mix design, a mean fraction of $30 \%$ of the total concrete volume was chosen to satisfy spread and V-funnel flow requirements of SCC and to prevent any blocking effect.

The medium-size aggregates had a specific gravity (SG) of 2.66 and an absorption capacity (AC) of $1.00 \%$. 


\section{Fine aggregates}

Two types of fine aggregates were used in the mortar and concrete mixes:

- $\quad$ Manufactured sand with particle sizes ranging from 0.075 to $4 \mathrm{~mm}$.

- Natural sand with particle sizes ranging from 0.075 to $1.18 \mathrm{~mm}$.

The specific gravity (SG) and the absorption capacity (AC) values for each type of fine aggregates are listed in Table 3.

TABLE 3

Fine Aggregate Specifications

\begin{tabular}{|l|c|c|}
\hline Material & SG & AC (\%) \\
\hline Crushed Sand & 2.52 & 2.70 \\
Crushed Sand without Fines & 2.49 & 1.00 \\
Natural Sand & 2.62 & 0.80 \\
Fine Aggregates composed of 45\% Crushed Sand \& 55\% & 2.56 & - \\
Natural Sand & 2.75 & - \\
Fines & \\
\hline
\end{tabular}

\section{Powder}

The powder fraction of the concrete mix includes any particle having a size smaller than $0.075 \mathrm{~mm}$, comprising the cement and the filler. SCC necessitates the use of high powder content to maintain stability. Type I cement with a specific gravity of 3.2 was used in the mix. The crushing powder contained in the aggregates, constituted the filler that was found to have a specific gravity of 2.75 . The ratio of the water to powder content was maintained constant at a ratio of 0.33 .

\section{Superplasticizers}

Tables 4 and 5 show the properties of the second generation (SNF-based) and third generation (PCE-based) superplasticizers as provided by the manufacturer.

\section{TABLE 4}

\section{Properties of the Second Generation}

\begin{tabular}{|c|c|}
\hline \multicolumn{2}{|c|}{ SNF-based admixture } \\
\hline In compliance with & ASTM C494 Type F \\
Water reduction & $30 \%$ \\
Dosage by cement weight & $0.8-3.0 \%$ \\
Specific gravity & $1.2 \mathrm{~kg} / \mathrm{litre}$ \\
Solid content & $35 \%$ \\
\hline
\end{tabular}


TABLE 5

Properties of the Third Generation Superplasticizer

\begin{tabular}{|l|c|}
\hline \multicolumn{2}{|c|}{ PCE-based admixture } \\
\hline In compliance with & EN 934-2 \\
Water reduction & $30 \%$ \\
Dosage by cement weight & $0.25-2.0 \%$ \\
Specific gravity & $1.07 \mathrm{~kg} / \mathrm{litre}$ \\
Solid content & $30 \%$ \\
\hline
\end{tabular}

\section{Mix proportioning}

In phase I, the constituents were proportioned in terms of percentage of mortar volume where $45 \%$ of the total volume of mortar was dedicated to fine aggregates while the remaining 55\% was reserved for the paste. The paste consists of a blend of powder, water and superplasticizer and was designed considering a free water to cement ratio of 0.35 .

Since mortars should constitute around $60 \%$ to $70 \%$ of the total concrete volume, the concrete mix design for Phase II was carried using a mortar content of $70 \%$, while the remaining 30\% was reserved for medium size coarse aggregates. It should be noted that the same water to powder ratio adopted in the mortar mixes of Phase I was maintained in the design of the concrete mixes of Phase II to obtain consistent results. The water required to saturate the surface of medium size coarse aggregates was added.

The same procedure followed in the computation of mortar mixes was adopted in concrete mix proportioning.

\section{Material preparation}

All materials were oven-dried. The crushed sand was sieved then washed over sieve \#200 to separate the crushing powder and eliminate any residues that may be covering the surface areas of fine aggregates. Fines passing sieve \#200 were kept for later use with controlled quantities to maintain constant water to powder ratio. Similarly, the medium size crushed limestone aggregates were washed over sieve \#4 to eliminate fine particles. The material was weighed with reference to the mix proportioning presented in Table 6 .

In Phase I, a small laboratory mixer was used to manipulate the speed and the time of mixing, ensuring more accurate outcomes. The same mixing sequence was adopted for all mortar mixes. The fine aggregates were wet mixed first for 1 minute. Then, after adding all the material (excluding the superplasticizer) to the container, the resulting mortar was mixed for another minute, after which the superplasticizer was added and all the mix was blended for three additional minutes to guarantee that the superplasticizer started to function effectively.

In Phase II, a small laboratory mixer with a capacity of $0.1 \mathrm{~m}^{3}$ was used. The inner surface of the mixer was wetted before the addition of materials to minimize any loss in free water. The same mixing speed was maintained for all concrete trial mixes. A unified mixing 
sequence was followed: the dry aggregates were added first combined with 1 litre of water. One minute later, cement was added with the remaining quantity of water and all the materials were mixed for another minute. At the end, the superplasticizer was added to the mixture and the final mix was blended for six additional minutes.

\section{TABLE 6}

\section{Summary of Mix Proportioning for Concrete Mixes}

\begin{tabular}{|l|c|}
\hline \multicolumn{1}{|c|}{ Constituent Materials } & Mix Proportioning \\
\hline Water to powder ratio & 0.33 \\
\% of medium aggregates of total weight of aggregates & 48.8 \\
\% of crushed sand of total weight of aggregates & 23.7 \\
\% of natural sand of total weight of aggregates & 27.5 \\
\% of medium aggregates of total volume of aggregates & 29.8 \\
\% of crushed sand of total volume of aggregates & 14.5 \\
\% of natural sand of total volume of aggregates & 16.8 \\
Cement content $\mathbf{( k g / \mathbf { m } ^ { 3 } )}$ & 559 \\
Powder content $\left(\mathbf{k g} / \mathbf{m}^{\mathbf{3}}\right)$ & 585 \\
Free water content $\left(\mathbf{k g} / \mathbf{m}^{\mathbf{3}}\right)$ & 195 \\
\hline
\end{tabular}

The materials used in mortar and concrete mixes were supplied from a unique source to limit the variability of the aggregates.

\section{RESULTS AND DISCUSSION}

Phase I: fresh and hardened mortar properties

Fresh properties

Results of the spread flow and the V-funnel tests conducted on mortar mixes containing either second generation superplasticizer (SNF) or third generation superplasticizer (PCE) are presented in Table 7.

\section{TABLE 7}

Mortar Mixes - Summary of Rheological Results ( $/$ /p = 0.33; mixing time = 3 min.)

\begin{tabular}{|c|c|c|c|c|c|c|c|}
\hline Mortar Mix & $\%$ SP & $\begin{array}{c}\text { Spread } \\
\text { Flow } \\
\text { Test } \\
(\mathbf{m m}) \\
\end{array}$ & $\begin{array}{l}\text { V-Funnel } \\
\text { Flow Time } \\
\text { (sec) }\end{array}$ & Mortar Mix & $\%$ SP & $\begin{array}{c}\text { Spread Flow } \\
\text { Test (mm) }\end{array}$ & $\begin{array}{l}\text { V-Funnel Flow } \\
\text { Time (sec) }\end{array}$ \\
\hline- & - & - & - & $\mathrm{PCE}^{* *-0.40 \%}$ & 0.40 & 60 & 16.8 \\
\hline- & - & - & - & PCE**-0.61\% & 0.61 & 295 & 5.7 \\
\hline SNF*-0.80\% & 0.80 & 60 & 20 & PCE**-0.82\% & 0.82 & 297 & 4.3 \\
\hline SNF $^{*-1.11 \%}$ & 1.11 & 130 & 6.29 & $\mathrm{PCE}^{* *-1.03 \%}$ & 1.03 & 300 & 3.36 \\
\hline
\end{tabular}




\begin{tabular}{|l|l|l|l|c|c|c|c|}
\hline SNF*-1.20\% & 1.20 & 190 & 4.73 & PCE**-1.28\% & 1.28 & 305 & 3.42 \\
SNF*-1.46\% & 1.46 & 235 & 4.61 & PCE**-1.46\% & 1.46 & 310 & 3.56 \\
SNF*-1.65\% & 1.65 & 285 & 4.29 & PCE**-1.69\% & 1.69 & 315 & 3.84 \\
SNF*-1.81\% & 1.81 & 280 & 5.54 & PCE*-1.83\% & 1.83 & 320 & 4.57 \\
SNF*-2.03\% & 2.03 & 275 & 5.1 & PCE**-2.07\% & 2.07 & 320 & 4.47 \\
SNF*-2.21\% & 2.21 & 275 & 4.68 & - & - & - & - \\
SNF*-2.40\% & 2.40 & 280 & 5.2 & - & - & - & - \\
SNF*-2.60\% & 2.60 & 290 & 4.74 & - & - & - & - \\
SNF*-2.80\% & 2.80 & 280 & 5.24 & - & - & - & - \\
SNF*-3.00\% & 3.00 & 280 & 5.17 & - & - & - & - \\
\hline
\end{tabular}

* SNF denotes Sulphonated Naphthalene Formaldehyde-based admixture or Second generation superplasticizer.

** PCE denotes Polycarboxylate Ethers-based admixture or Third generation superplasticizer The collected data including the two sets of mortar mixes were plotted. The charts shown in Figure 3 illustrate the variation of the spread flow as a function of the type and the dosage of superplasticizer for constant water to powder ratio of 0.33 .

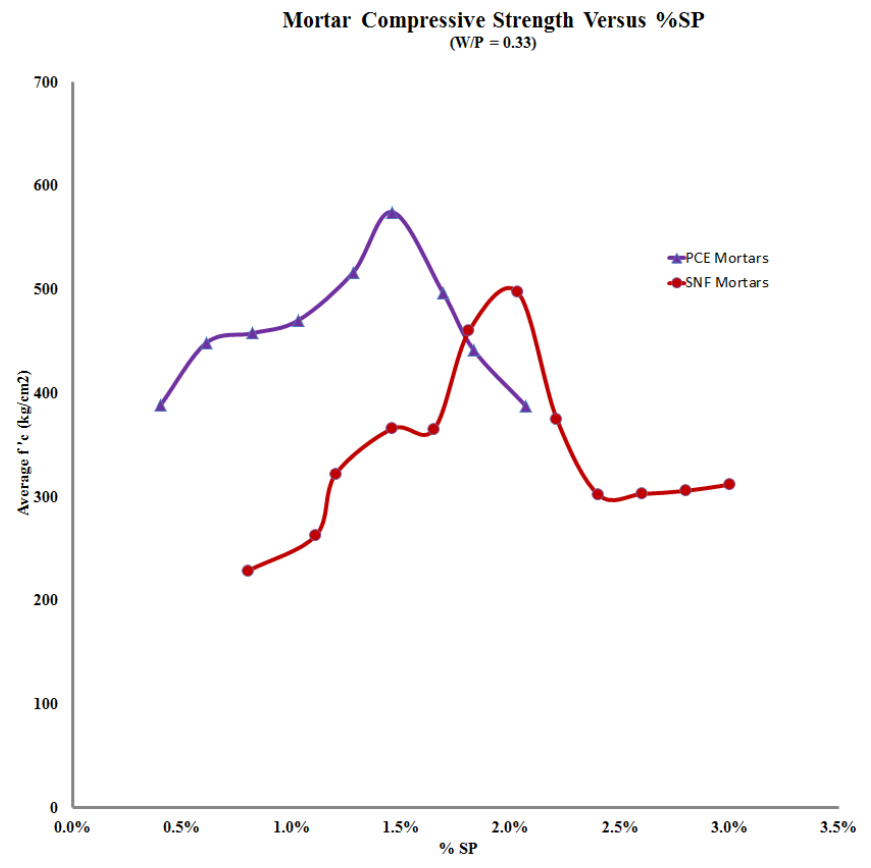

Figure 3. Mortar spread flow versus percentage of superplasticizer (Harkouss \&

Hamad, 2014) 
Figure 4 displays the variation of the V-Funnel flow time as a function of the type and dosage of superplasticizer.

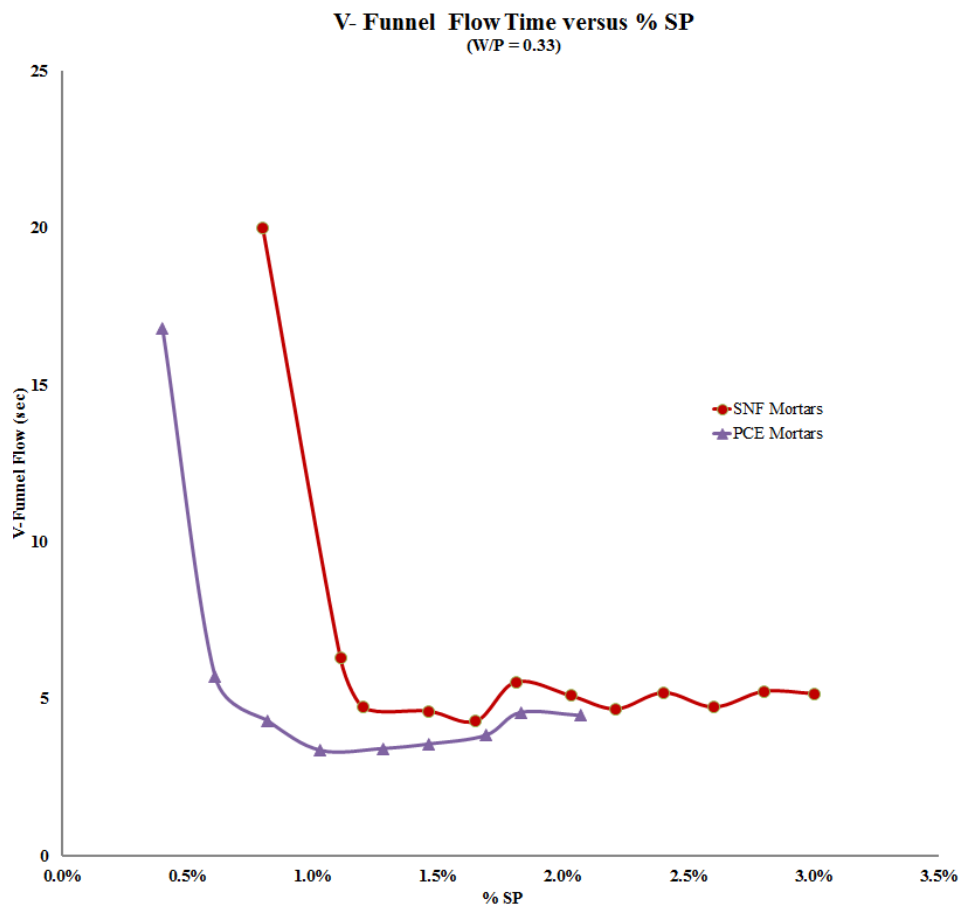

Figure 4. Mortar V-funnel flow versus percentage of superplasticizer

With reference to the UCL (Domone 2009) graphs presented in Figure 1, a range of mortar spread flow of 265 to $315 \mathrm{~mm}$ corresponding to a concrete slump flow of 650 to 800 $\mathrm{mm}$ is considered acceptable to create self-compactibility properties.

\section{Hardened properties}

The compressive strengths of hardened mortar cubes at the age of 7 days are reported in Table 8 .

\section{TABLE 8}

Mortar Mixes - Summary of Hardened Cube Compressive Strength $(\mathrm{w} / \mathrm{p}=\mathbf{0 . 3 3}$; mixing time $=3$ min.)

\begin{tabular}{|c|c|c|c|c|c|}
\hline Mortar Mix \# & \% SP & $\begin{array}{c}\text { Average 7-days Cube } \\
\text { Strength }\left(\mathbf{k g} / \mathbf{c m}^{2}\right)\end{array}$ & Mortar Mix \# & \% SP & $\begin{array}{c}\text { Average 7-days Cube } \\
\text { Strength }\left(\mathbf{k g} / \mathbf{c m}^{2}\right)\end{array}$ \\
\hline- & - & - & PCE** 0.40\% & 0.40 & 389 \\
\hline
\end{tabular}




\begin{tabular}{|c|c|c|c|c|c|}
\hline- & - & - & PCE** - 0.61\% & 0.61 & 449 \\
\hline $\mathrm{SNF}^{*}-\mathbf{0 . 8 0 \%}$ & 0.80 & 229 & PCE $^{* *}-0.82 \%$ & 0.82 & 458 \\
\hline SNF $^{*}-1.11 \%$ & 1.11 & 263 & PCE ** $-1.03 \%$ & 1.03 & 470 \\
\hline $\mathrm{SNF}^{*}-1.20 \%$ & 1.20 & 322 & PCE** $-1.28 \%$ & 1.28 & 517 \\
\hline $\mathrm{SNF}^{*}-1.46 \%$ & 1.46 & 366 & PCE** $-1.46 \%$ & 1.46 & 575 \\
\hline $\mathrm{SNF}^{*}-1.65 \%$ & 1.65 & 365 & PCE** $-1.69 \%$ & 1.69 & 497 \\
\hline $\mathrm{SNF}^{*}-1.81 \%$ & 1.81 & 460 & PCE** $-1.83 \%$ & 1.83 & 442 \\
\hline $\mathrm{SNF}^{*}-\mathbf{2 . 0 3} \%$ & 2.03 & 498 & PCE** $-2.07 \%$ & 2.07 & 388 \\
\hline $\mathrm{SNF}^{*}-2.21 \%$ & 2.21 & 375 & - & - & - \\
\hline $\mathrm{SNF}^{*}-2.40 \%$ & 2.40 & 302 & - & - & - \\
\hline $\mathrm{SNF}^{*}-2.60 \%$ & 2.60 & 303 & - & - & - \\
\hline $\mathrm{SNF}^{*}-2.80 \%$ & 2.80 & 306 & - & - & - \\
\hline $\mathrm{SNF}^{*}-\mathbf{3 . 0 0 \%}$ & 3.00 & 312 & - & - & - \\
\hline
\end{tabular}

* SNF denotes Sulphonated Naphthalene Formaldehyde-based admixture or Second generation superplasticizer.

** PCE denotes Polycarboxylate Ethers-based admixture or Third generation superplasticizer.

The plot in Figure 5 presents the estimated average compressive strength at 7 days as a function of the dosage for each type of superplasticizer.

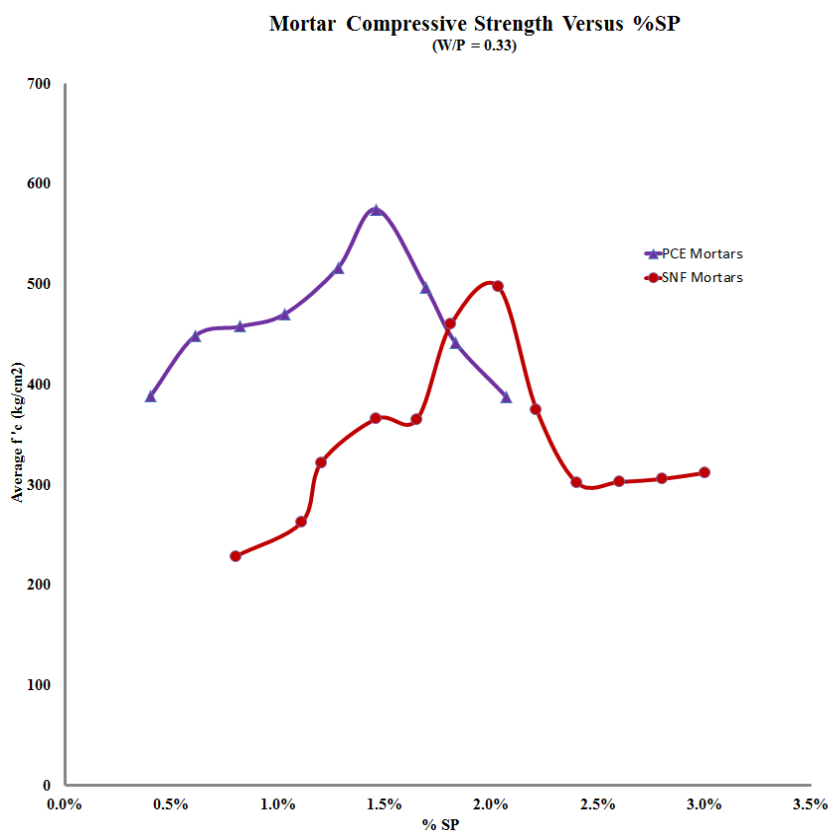

Figure 5. Average 7-days cube compressive strength versus superplasticizer dosage. 


\section{DISCUSSION}

Figure 3 demonstrates that mixes produced using identical proportions of constituent materials but different superplasticizer types, exhibited similar response to incremental dosage of superplasticizer. Therefore, whether SNF or PCE admixture is used, the corresponding charts start with a steep slope indicating a high rate of increase in the spread flow at the beginning until an optimal maximum dosage of admixture is reached after which any subsequent increase in the superplasticizer content will have little effect on the flowability. It was noticeable that the rate of increase in the fluidity of PCE mortars is greater than that of SNF mortars.

The experiments have proven that the maximum fluidity reached using PCE admixture could not be reached even when the maximum allowable dosage of SNF admixture was used considering constant water to powder ratio. The maximum spreads when testing mixes produced using second generation and third generation superplasticizers were 280 and $320 \mathrm{~mm}$ respectively.

In contrast to the spread flow chart, Figure 4 shows a sharp decrease in the V-funnel flow rate for the first few samples in each sequence of mortar mixes until an optimal superplasticizer dosage is reached where the flow rate became steady. The two slopes marking the starting phase of the spread flow curve for SNF and PCE admixtures are approximately parallel.

The comparison of the two mortar mixes identical except for the different generation of superplasticizer used, demonstrated a significant difference in the flowability of the mix. Through linear interpolation, the computations have shown that self-compactibility properties corresponding to a mortar spread of $265 \mathrm{~mm}$ were achieved at $0.58 \%$ of PCE admixture and $1.58 \%$ of SNF admixture, a dosage approximately 2.7 times that required by PCE mortars.

Tests revealed that a percentage of $1.65 \%$ of SNF and $0.61 \%$ PCE superplasticizer can be considered as optimal dosage since beyond these values, any further increase in the dosage of admixture will have little effect on the mortar fluidity.

Observations indicated the occurrence of bleeding at 1 minute from the time when the spread test was carried in mortar mixes containing $1.65 \%$ of SNF admixture and $1.83 \%$ of PCE admixture. Although polycarboxylate-based superplasticizers provide more consistency, bleeding in PCE mortars occurred for a higher dosage when compared to SNF mortars; this is caused by the chemical composition of the viscous solution that provides better stability retention and maintains moderate viscosity even at high dosages.

The charts shown in Figure 5 representing the mortar compressive strength as a function of the admixture content reveal a specific superplasticizer dosage for each sequence of mortar mixes for which a maximum mortar compressive strength can be reached. Consequently, SNF mortar mixes reached an average 7 days compressive strength of 498 $\mathrm{kg} / \mathrm{cm}^{2}$ at a dosage of $2.03 \%$ of SNF second generation superplasticizer while the cube strength was $575 \mathrm{~kg} / \mathrm{cm}^{2}$ at a dosage of $1.46 \%$ of PCE third generation superplasticizer. 
Phase II: fresh \& hardened concrete properties

Fresh properties

Table 9 lists the fresh properties of concrete trial mixes made using second generation superplasticizer.

TABLE 9

Fresh Properties of Concrete Trial Mixes Made with Second Generation SP $(w / p=0.33)$

\begin{tabular}{|l|c|c|c|c|c|}
\hline Concrete Mix \# & \% SP & Slump & $\begin{array}{c}\text { Spread Flow } \\
\text { Test }(\mathbf{m m})\end{array}$ & $\begin{array}{c}\text { V-Funnel } \\
\text { Test (secs) }\end{array}$ & $\begin{array}{c}\text { L-Box Test } \\
\left(\mathbf{H}_{2} / \mathbf{H}_{\mathbf{1}}\right)\end{array}$ \\
\hline SNF-CM*-1.55\% & 1.55 & 175 & - & - & - \\
SNF-CM*-1.60\% & 1.60 & 220 & 450 & - & - \\
SNF-CM*-2.20\% & 2.20 & - & 700 & 9.06 & 0.78 \\
\hline
\end{tabular}

*SNF-CM indicates concrete trial mixes made with Sulphonated Naphthalene Formaldehydebased admixture or Second generation superplasticizer.

Table 10 quantifies the passing and filling ability of SCC mixes made using third generation superplasticizer specified for precast concrete plants and ready mix concrete batching plants. The slump test was conducted in accordance to ASTM C143 (2010) and ASTM 1611 (2009). The V-funnel and the L-box test were carried with reference to EN12350-9 (2010) and EN12350-10 (2010) respectively.

\section{TABLE 10}

Fresh Properties of Concrete Trial Mixes Made with Third Generation SP $(w / p=0.33)$

\begin{tabular}{|l|c|c|c|c|}
\hline Concrete Mix \# & $\begin{array}{c}\text { \% } \\
\text { SP }\end{array}$ & $\begin{array}{c}\text { Spread Flow } \\
\text { Test }(\mathbf{m m})\end{array}$ & $\begin{array}{c}\text { V-Funnel Test } \\
(\text { secs })\end{array}$ & L-Box Test $\left(\mathbf{H}_{2} / \mathbf{H}_{\mathbf{1}}\right)$ \\
\hline PCE-CM ${ }^{*} \mathbf{- 1 . 5 0 \%}$ & 1.5 & 750 & 8.65 & 0.97 \\
PCE-CM**-1.60\% & 1.60 & 790 & 2.30 & 1.00 \\
\hline
\end{tabular}

* PCE -CM indicates concrete trial mixes made with Polycarboxylate Ethers-based admixture or Third generation superplasticizer.

\section{Hardened properties}

The hardened properties were tested for two identical concrete mixes except for the type of the constituent superplasticizer with identical mix proportioning and a constant dosage of superplasticizer of $1.60 \%$ : a value that has proven to give acceptable compactibility characteristics for the fresh concrete mixes while eliminating any possibility of bleeding and segregation.

Standard 150x300 mm cylinders were cast using SNF and PCE concrete trial mixes, and tested to determine the concrete compressive strength $\mathrm{f}^{\prime} \mathrm{c}$ at different ages according to ASTM C39 (2012), the tensile strength $\mathrm{f}_{\mathrm{t}}$ following to ASTM C496 (2011), and the modulus of elasticity $E_{c}$ with reference to ASTM C469 (2010). 
Standard plain concrete beams $(150 \times 150 \times 530 \mathrm{~mm})$ were also prepared to determine the flexural strength or modulus of rupture $\mathrm{f}_{\mathrm{r}}$ in compliance with ASTM C78 (2010). Results are shown in Table 11.

For comparison purposes, all the experimental values were normalized at a common concrete strength of $600 \mathrm{~kg} / \mathrm{cm}^{2}$. Normalization was conducted by multiplying the tensile strength, the flexural strength, the modulus of elasticity and the modulus of rupture values by $\left(600 / \mathrm{f}^{\prime}\right)^{0.5}$ where $\mathrm{f}^{\prime} \mathrm{c}$ is $579 \mathrm{~kg} / \mathrm{cm}^{2}$ for SNF concrete mixes and $624 \mathrm{~kg} / \mathrm{cm}^{2}$ for PCE concrete mixes.

\section{DISCUSSION}

Laboratory experiments have proven that concrete mixes made using two types of third generation superplasticizer produced for different applications had different retarding effects. Concrete mixes made using PCE (specified for precast concrete plants) became very hard to manipulate a short time after the spreading of the mix, while PCE (made for RMP) had shown better workability retention. Also, concrete mixes made with PCE maintained more stable and cohesive state after casting while the usage of PCE made concrete more prone to bleeding.

Experimental tests conducted on concrete mixes made using second generation superplasticizers and presented in Table 9 revealed that a $2.20 \%$ of SNF admixture is necessary to produce self-compacting properties.

Comparing the fresh properties of concrete mixes with the ones for mortar mixes, it was found that the UCL (Domone 2009) diagram displaying the concrete spread as a function of mortar spread for different coarse aggregate contents is not applicable for second generation superplasticizers, while it has demonstrated consistency for third generation SP independently from the properties of the constituent materials.

Experiments on hardened concrete properties shown in Table 11 revealed higher early compressive strength gain (from 1 - 4 days) for concrete mixes made with second generation SNF-based superplasticizer.

However, higher compressive strength of concrete at 7 days and later ages was distinctive for concrete mixes made with third generation superplasticizers specified for ready mix plants. The greater compressive strength was accompanied by a slightly higher tensile strength, as well as a more pronounced modulus of elasticity and modulus of rupture. The reasonable cause can be related to the enhanced dispersion mechanism and the more relevant hydration process associated with the use of third generation superplasticizer. 
TABLE 11

Hardened Concrete Properties

\begin{tabular}{|c|c|c|c|}
\hline Property & Age (days) & $\begin{array}{l}\text { SNF-CM*- } \\
1.60 \%\end{array}$ & PCE-CM**-1.60\% \\
\hline \multirow{5}{*}{$\begin{array}{l}\text { Cylinder Compressive } \\
\text { Strength } \mathbf{f}_{\mathrm{c}},\left(\mathrm{kg} / \mathrm{cm}^{2}\right)\end{array}$} & 1 & 92 & 78 \\
\hline & 4 & 363 & 345 \\
\hline & 7 & 379 & 463 \\
\hline & 13 & 483 & 565 \\
\hline & 65 & 579 & 624 \\
\hline$E_{c}-$ Experimental $\left(\mathrm{kg} / \mathrm{cm}^{2}\right)$ & - & 331,031 & 351,331 \\
\hline$E_{c}-\operatorname{Normalized}\left(\mathrm{kg} / \mathrm{cm}^{2}\right)$ & - & 336,981 & 344,508 \\
\hline $\begin{array}{c}f_{t} \text { avg }- \text { Experimental } \\
\left(\mathrm{kg} / \mathrm{cm}^{2}\right)\end{array}$ & - & 38 & 43 \\
\hline$f_{t}-$ Normalized $\left(\mathrm{kg} / \mathrm{cm}^{2}\right)$ & - & 39 & 42 \\
\hline $\mathbf{f}_{\mathrm{r}}-$ Experimental $\left(\mathrm{kg} / \mathrm{cm}^{2}\right)$ & - & 51 & 60 \\
\hline$f_{r}-\operatorname{Normalized}\left(\mathrm{kg} / \mathrm{cm}^{2}\right)$ & - & 52 & 59 \\
\hline
\end{tabular}

*SNF-CM indicates concrete trial mixes made with Sulphonated Naphthalene Formaldehydebased admixture or Second generation superplasticizer.

** PCE-CM indicates concrete trial mixes made with Polycarboxylate Ethers-based admixture or Third generation superplasticizer.

\section{CONCLUSIONS AND RECOMMENDATIONS}

During the first phase of the research, laboratory tests were conducted on identical small scale mortar mixes made using two types of superplasticizers added at incremental dosages. The two types are second generation sulphonated naphthalene formaldehyde-based superplasticizer (SNF) and third generation polycarboxylate ether-based superplasticizer for precast plants (PCE). The outcomes revealed that third generation PCE-based superplasticizer induces more efficient dispersion leading to self-compactibility characteristics at significantly lower superplasticizer dosages and producing ultimate consistency levels that are hardly achievable with SNF-based superplasticizers. On the other hand, the viscous nature of third generation superplasticizers provides mortars with high stability and segregation resistance differently from the case of second generation superplasticizers.

Tests on hardened mortars demonstrated that for a constant water to cement ratio, a maximum compressive strength can be encountered for a specific dosage of superplasticizer. Further investigation in the applicability of this topic can be beneficial in the development of a successful method for the identification of the proper combination of maximum consistency levels and maximum compressive strengths through the selection of the appropriate dosage of admixture. 
Similarly, in the second phase of the research program, the superior dispersion effect of PCE superplasticizers was visible during the concrete trial mixing stage.

Testing the fresh properties of identical concrete mixes made with second or third generation superplasticizers revealed limitations on the applicability of the UCL diagram. The tests on SNF concrete mixes demonstrated a different relationship between the concrete and mortar spread results.

Conversely, in the case where PCE superplasticizers were incorporated, the UCL diagram has proven excellent representation of the correlation between concrete slump as function of mortar flow irrespective of the variability in the constituent materials.

The tests on hardened concrete cylinders and plain concrete beams were of particular importance in pointing on some of the effects of enhanced flowability on the strength of concrete at a later age. It was noticed that the higher consistency of SCC was accompanied by a higher compressive strength starting from the age of 7 days while the splitting strength and the modulus of rupture were slightly greater for the PCE specimen than it was for the SNF specimen. The analysis of the experimental results led to the assumption that the more efficient dispersion of polycarboxylate-based superplasticizers constitutes a possible cause for the differences in the strength of hardened concrete mixes. These results refute the hypothesis declaring that the high consistency of concrete will lead to inferior concrete strengths.

The outcomes of the two phases led to establishing an optimal concrete mix design with a superplasticizer content of $1.6 \%$ of the total weight of cement that will be used in the reinforced concrete beam study during the third phase of the current research.

\section{ACKNOWLEDGEMENTS}

The authors gratefully acknowledge the University Research Board at the American University of Beirut for supporting this program. Also, the assistance of Mr. Helmi El-Khatib, Supervisor of the testing laboratories at AUB, is appreciated.

\section{REFERENCES}

ACI Committee 237 2007. Self-consolidating concrete. American Concrete Institute, Farmington Hills, MI.

ASTM Standard C143/ C143M 2010. Standard test method for slump of hydraulic-cement concrete. ASTM International, West Conshohocken, PA.

ASTM Standard C1611/ C1611M 2009. Standard test method for slump flow of selfconsolidating concrete. ASTM International, West Conshohocken, PA.

ASTM Standard C39 / C39M 2012. Standard test method for compressive strength of cylindrical concrete specimens. ASTM International, West Conshohocken, PA.

ASTM C496 / C496M 2011. Standard test method for splitting tensile strength of cylindrical concrete specimens. ASTM International, West Conshohocken, PA.

ASTM C469 / C469M 2010. Standard test method for static modulus of elasticity and Poisson's ratio of concrete in compression. ASTM International, West Conshohocken, PA. 
ASTM C78 / C78M 2010. Standard test method for flexural strength of concrete (using simple beam with third-point loading). ASTM International, West Conshohocken, PA.

ASTM Standard C494/ C494M 2012. Standard specification for chemical admixtures for concrete. ASTM International, West Conshohocken, PA.

Domone, P., Jin, J. and Chai, H. 1999. Optimum mix proportioning of self-compacting concrete. pp. 277-285 In: R. Dhir and M. Jones (eds.), Proceedings of International Conference on Innovation in Concrete Structures, Design and Construction, Thomas Telford, London.

Domone, P. 2009. Proportioning of self-compacting concrete: the UCL method. Department of civil, environmental and geometic engineering, University College London, London, UK.

Dransfield, J. 2003. Admixtures for concrete, mortar and grout. In: J. Newman and B.S. Choo (eds.), Advanced concrete technology: constituent materials, Oxford, Great Britain: Elsevier Butterworth Heinemann.

EFNARC 2002. Specification and guidelines for self-compacting concrete: specification, production and use.

EFNARC 2005. The European guidelines for self-compacting concrete: specification, production and use.

EN 934-2 2009. Admixtures for concrete, mortar and grout - Part 2: concrete admixtures Definitions, requirements, conformity, marking and labeling.

EN 12350-9 2010. Testing fresh concrete - Part 9: self-compacting concrete - V-funnel test.

EN 12350-10 2010. Testing fresh concrete - Part 10: self-compacting concrete - L-box test.

Gaimster, R. and Dixon, N. 2003. Self-compacting concrete. In: J. Newman and B.S. Choo (eds.), Advanced concrete technology: processes. Oxford, Great Britain: Elsevier Butterworth Heinemann.

Harkouss, R. and Hamad, B. 2014. Overview studies of high strength self-consolidating concrete. World Academy of Science, Engineering and Technology, International Science Index 90. International Journal of Civil, Architectural, Structural and Construction Engineering, 8(6): 682-686.

Walraven, J. 2003. Structural applications of self compacting concrete. In: O. Wallevik and I. Nielsson (eds.), pp 15-22 In Proceedings of 3rd RILEM International Symposium on Self Compacting Concrete, Reykjavik, Iceland, RILEM Publications. 